\title{
proposed amendment to the constillution and by-laws
}

The Council of the American Meteorological Society on January 21, 1975, voted to recommend to the membership of the Society that the proposed amendment to the By-Laws set forth below be adopted:

Delete Article VIII, Code of Ethics, and substitute therefor the following. (The present Code of Ethics is printed in the left column and the proposed Code in the right column below for convenience of comparison.)

Code of Ethics-present code

\section{Article VIII. Code of Ethics}

In order that the dignity and honor of the meteorological profession may be upheld, that its sphere of usefulness and its contributions to society may be extended, and that meteorologists may be guided as individuals or in association with other meteorologists, the Council of the American Meteorological Society has adopted the following Code of Ethics and Conduct for compliance by the Society's membership:

A. Relationship with the profession as a whole.

1. The meteorologist will endeavor to keep abreast of scientific and technical developments within the profession, and will constantly strive for improvements.

2. He will endeavor to contribute new knowledge to meteorology by making known to the scientific world results of his significant work or research through the media of technical or scientific publications or meetings.

B. Relationship of the meteorologist with his fellow meteorologists.

1. The meteorologist will not engage in unfair competition with other members of his profession;

a) He will not knowingly solicit another meteorologist's client(s);

b) He will not interpose between another meteorologist and his prospective client while negotiations or project developments are in progress;

c) He will attempt to secure work on the basis of qualification and performance, not on lower fees;

d) He will not knowingly be associated in responsibility for work with meteorologists or organizations who violate ethical practices.

2. He will not discredit his fellow meteorologists:

a) He will not directly or indirectly injure the professional reputation, prospects, or practice of an-
Proposed Revised Code of Ethics

\section{Article VIII. Code of Ethics}

In order to protect the public interest; to enhance the usefulness of the meteorological and related professions to humanity; to uphold the dignity and honor of the profession and to provide guidance for individual members, corporate members, or for members in association with other professionals, the American Meteorological Society has adopted the following Code of Professional Ethics for compliance by the Society's membership:

A. Relationship with the profession as a whole.

1. The member will conduct himself in a manner to reflect dignity and honor on his profession.

2. The member will endeavor to keep abreast of scientific and technical developments within the professions, and will constantly strive for improvements.

3. He will endeavor to contribute new knowledge to the profession by making known to the scientific world results of his significant work or research through the media of technical or scientific publications or meetings.

B. Relationship of the member to fellow professionals.

1. He will not engage in unfair competition with other members of his or other professions, for example:

a) He will not knowingly interpose between another professional and his client or prospective client while contract negotiations or project work are in progress,

b) He will attempt to secure work on the basis of qualification and performance,

c) He will not knowingly be associated in responsibility for work with meteorologists or organizations who violate ethical practices.

2. He will not unfairly discredit his fellow professionals. However, he will present to the proper authority 
other meteorologist; however, he will present information on unethical, illegal, or unfair practice to the proper authority for action.

b) He will not review the work of another meteorologist for the same client, except with the other's full knowledge or consent, or unless the association of the other meteorologist has been terminated.

3. He will not take credit knowingly for work done by others; in publications or meetings, he will attempt to give credit where due.

C. Relationship of the meteorologist with his clients and the general public.

1. The meteorologist will base his practice on sound scientific principles applied in a scientific manner.

2. He will not direct his professional activities into practices generally recognized as being detrimental to or incompatible with the general public welfare.

3. He will fully advise his client before undertaking work for compensation as to the probability of success.

4. He will refrain from making exaggerated and unwarranted claims and statements;

a) Long-range predictions which demonstrate little or no skill over climatology shall be identified as outlooks, experimental predictions, or climatological expectancies, as appropriate;

b) Stated claims for skill and accuracy of predictions must be based on verification by valid statistical techniques;

c) General purpose forecasts will not be represented as being adequate for specific operations which are better served by specialized forecasts.

5. He will not use or display the official seal of the American Meteorological Society unless duly authorized by the Society.

6. The meteorologist, regardless of organization affiliation, will refer requests for service which are beyond his professional capabilities or his scope of service to those properly qualified. for action, information on unethical, illegal, or unfair practice on the part of members.

3. He will not take credit knowingly for work done by others; in publications or meetings, he will attempt to give credit where due.

C. Relationship of the member with his clients and the general public.

1. He will base his practice on sound scientific principles applied in a scientific manner.

2. He will not direct his professional activities into practices generally recognized as being detrimental to or incompatible with the general public welfare.

3. Before undertaking work for compensation, he will fully advise his client as to the probability of success.

4. He will refrain from making exaggerated and unwarranted claims and statements, for example:

a) Long-range predictions which demonstrate little or no skill over climatology shall be identified as outlooks, experimental predictions, or climatological expectancies, as appropriate,

b) Stated claims for skill and accuracy of predictions must be based on verification by valid statistical techniques,

c) General purpose forecasts will not be represented as being adequate for specific operations which are better served by specialized forecasts,

d) Claims for results from weather modification must be backed by data and prior testing to demonstrate that the claimed results might reasonably be expected.

5. He will not use or display the official seal of the American Meteorological Society unless duly authorized by the Society.

6. The member, regardless of organization affiliation, will refer requests for service which are beyond his professional capabilities or his scope of service to those properly qualified.
The proposed changes in the present Code were made for several reasons: First, the wording throughout has been changed slightly so as not to exclude the several professions represented in the society other than meteorologists; second, changes in tone in its initial statements have been made to reflect more clearly the dedication of the membership to the protection of the public intrest in addition to the promotion of the dig. nity and honor of the profession; and third, the code has also been changed so that it embraces all classes of membership, including corporation members.

The remaining changes stem from past experience with the code and represent clarifications and qualifications deemed necessary within the context of present interpretations of law and professional conduct. Any implication of the setting of prices or suppression of 
competition has been eliminated to conform to current interpretations of anti-trust laws.

In order to keep the code more generally applicable and yet not have to list every possible situation which might arise, Section B-1 and Section C-4 have been changed to make it clear that these are examples of what might be unethical conduct and the list is not all inclusive.

Section B-2, Item (b) has been eliminated. The board does not feel that reviewing the work of another mete- orologist is necessarily unethical. Clients and employers frequently require that the one adviser's work be reviewed by another, editors ask members to review the manuscripts and work of others, and government agencies ask members to review research proposals.

The Board of Professional Ethics and the four past chairmen of the Board approved these changes at a meeting in Denver on January 20, 1975, and the Council approved the changes on January 21, 1975.

Fifth Edition

\section{GURRIGULA IN THE ATMOSPHERIC AND OGEANOGRAPHIC (PHYSICAL/DYNAMICAL) SCIENCES: 1974}

\section{Colleges and Universities in the United States and Canada}

Announcing publication of a completely new version of a Society-sponsored series of biennial reports on academic curricula, which, for the first time, surveys colleges and universities having degrees or majors in physical and/or dynamical oceanography, and hydrology, as well as in the atmospheric sciences.

The report includes information, for 82 schools, on academic and key research personnel, types of degrees granted, undergraduate and/or graduate courses and credits, titles and authors of theses and dissertations in progress, and descriptions of special facilities.

The educational and reference information contained herein is an indispensable resource to prospective students, to those involved in career planning and counseling, and to the entire meteorological community.

Approximately 240 pages-price $\$ 5.00$

American Meteorological Society, 45 Beacon Street, Boston, Mass. 02108 